\section{Glove wearing: an assessment of the evidence}

J. Mew ${ }^{1}$
IN BRIEF
- Discusses glove wearing and its role in infection control.
- Examines the current available evidence regarding glove wearing and suggests that a logical approach should be taken.
- Weighs up the benefits and risks of glove wearing in relation to patients' health and safety.

Infection control is ubiquitous in current dental practice. However, it might not always be best practice to take the 'you can't be too safe' route without first weighing up all the available evidence, risks and benefits. This article will discuss the balance between the conflicting priorities in relation to glove wearing and infection control within the dental setting.

Human society has a natural desire to protect itself from danger and often the less tangible the risk, the greater the concern. Dangers such as radiation or bacterial infection often create apprehension coupled with a strong desire to be safe. The consensus is usually 'you can't be too safe'. Safety then becomes paramount and emotion can easily override more logical perceptions of cost, convenience and benefit. If current Xray safety precautions were applied universally, people would be kept out of sun light and all inter-continental flights banned. Clearly a balance needs to be struck between risk and benefit.

\section{ORIGINS OF GLOVE WEARING IN DENTISTRY}

Currently, anything less than total crossinfection control invites condemnation because it is seen as dirty and/or unhygienic. In 1990 a 22-year-old Californian girl Kimberly Bergalis developed AIDS, her concerned parents accepted her assurance that she was a virgin and had had no sexual contact with a possible carrier. The case was considered a mystery until she pointed a finger at her dentist, David Acer. He was known to be a homosexual and was found to be carrying the HIV virus. Subsequently they both died.

The HIV virus is actually quite difficult to transmit but press speculation encouraged the public to assume that dentists with HIV/

'Head of the London School of Facial Orthotropics, 1618 Pampisford Road, Purley, Greater London, CR8 2NE Correspondence to: John Mew

Email: john.mew@orthotropics.co.uk

\section{Refereed Paper}

Accepted 18 February 2015

DOI: 10.1038/sj.bdj.2015.292

${ }^{\circledR}$ British Dental Journal 2015; 218: 451-452
AIDS could infect patients either themselves or via their instruments if they had other patients with HIV/AIDS. Allegations were made that Acer had deliberately injected infected blood into Kimberly, This seems rather far-fetched; however, to this day we do not know if Acer was innocent or not. Kimberly was a beautiful girl with powerful parents and the case became a world sensation.

The American Dental Association recommended that dentists should wear gloves and the UK government followed insisting that the GDC made similar recommendations. Princess Diana tried to emphasise that AIDS was not easy to catch by shaking the hands of sufferers, one of whom said 'she shook my hand without her gloves on. That proves you can't get AIDS from normal social contact.' However, the public were frightened and some innocent victims of AIDS in the US had their homes burnt down and attitudes in the UK were equally tense. Shortterm precautions were consolidated by new recommendations on cross infection and the CQC was created to oversee their application.

\section{SAFETY IS RELATIVE?}

Some years ago British Rail decided not to install anti-collision equipment because of the cost. That effectively put a price of about $£ 6,000,000$ a head on passengers. How might this be related to the cost of eliminating dental hazards? Unfortunately, public perception often becomes more powerful than logic and it is often years before a balanced response can be achieved. While political correctness expects absolute safety, we have to accept that safety itself will always be relative. A good example has been the proliferation of 'protective glove wearing. For many years surgeons have worn gloves for invasive surgery', but glove wearing has now spread to many non-surgical fields and this is often more for political reasons than logical ones.

When the CQC was first set up, they naturally wished to ensure the highest levels of safety and required dental practices to adopt a modified form of barrier nursing. However, the dental profession found this onerous, inconvenient and expensive. Subsequently, these requirements were eased but if cross infection control is not absolute, it is at risk of becoming meaningless in terms of safety as it is very difficult to establish different levels of hygiene and know how scrupulously 'rules' are being observed.

\section{CROSS INFECTION RESEARCH}

Cross infection research is difficult because individual circumstances vary so widely. In general antigens are transferred from one animal or human reservoir to another, although most bacteria are host specific. We must remember that humans have evolved to live in symbiosis with countless millions of bacteria many of which are as dependent on us as we are on them and these lodgers are responsible for a sizable proportion of our body weight.

One important feature, not always appreciated, is that the number of bacteria or viruses transferred in any one incident may be more important than their virulence. For instance, if mice are infected with a small number of pneumococci they will survive but if the dose is multiplied by ten times about half will die. If it is multiplied by ten again (to the size of a pinhead) all the mice die. This is simply because the defence systems in the body are overwhelmed, especially if the host has not experienced that particular type of infection previously. This was known in India as long ago as the fifteenth century when they used 
very small doses of material derived from smallpox crusts to protect people from the disease, and it seems possible that one day this approach could provide natural immunity to many dangerous antigens.

The spread of infection is usually by inhalation or ingestion but may sometimes occur through open wounds or during surgery. Inhalation of airborne antigens is probably most common and routinely takes place during every conversation with colleagues and patients. However, the pathogens are usually introduced in small enough quantities for the recipient's defence system to cope. We receive large numbers of such infections each day which is the principal reason why dentists and other healthcare professionals are less susceptible to most infections.

Ingested antigens may be taken in in much larger quantities; for instance, there are frequently over a million bacteria in a millilitre of tap water and if the organism is pathogenic and able to survive the acid in the stomach these can be the source of a fatal infection. This is because of the large number of pathogens that may be ingested at any one time. Again it is often the quantity rather than the virulence that matters.

Research has confirmed that barrier nursing is a good defence but to be effective it must be scrupulous. Human skin forms a near total barrier. However, some bacteria are able to penetrate the mucous membrane of the mouth, nose or genitalia but usually only if there is a lesion. Naturally, the periodontal membrane is a weak point in any mouth.

\section{HOW ABSOLUTE CAN PREVENTION BE?}

Clearly hygiene and sterility are important but how absolute can prevention be? I think we have to admit that outside total barrier nursing, bacteria and viruses will always be floating around and we have to decide what degree of compromise we are prepared to accept. Gloves are a total barrier but within the average dental surgery most of them become contaminated as they are put on and they are quite often punctured during a range of dental procedures. In addition the number of bacteria on them is likely to be increased every time the clinician touches an instrument or the patient. We would be naive to believe that cross contamination can be prevented in most medical or dental clinics.

Hand hygiene is universally recommended as the most effective method for preventing cross infection. ${ }^{1}$ Also hand scrubbing and alcohol handrubs have proved to be very effective at reducing cross infection. ${ }^{2}$ However, even a thorough brushing will still leave many bacteria on the hands and wrists although these are in small quantities. Research has not yet confirmed if, in non-surgical situations, glove wearing is significantly more effective at preventing infection than thorough hand scrubbing. This is partly because gloved clinicians, particularly in non-surgical situations, tend to develop a sense of immunity and may touch a number of potentially infected items. Also they may scrub their hands less frequently, particularly as it is difficult to put gloves on wet hands. NICE guidelines ${ }^{1}$ recently recommend that hands are also washed 'immediately after removal of gloves' but they report that this recommendation is widely ignored. Appropriately, the GDC make many recommendations on 'hand decontamination' but does not insist on glove wearing.

In summary, individual bacteria on instruments or hands are probably of little concern, the real danger is from particulate blocks of material containing large numbers of bacteria, such as may be found on scalers or instruments contaminated with blood. The research appears to show that scrupulous scrubbing of instruments and hands may achieve almost as much sterilisation as disinfectants but there is a severe shortage of good scientific studies.

\section{OTHER CONSIDERATIONS}

So far we have only considered the benefits of sterility. There are, however, some adverse aspects of cross infection control. Firstly the loss of dexterity when wearing gloves. The fingertips have more sensory nerve endings than anywhere else in the body and many clinicians complain of 'a reduction in tactile sensation and reduced grip which can make procedures even more challenging and many of these procedures demand holding equipment, ie a handpiece, for long periods. ${ }^{3}$.

However, slightly to one side of this discussion there are some more subtle considerations. It is now generally accepted that the body's greatest defence mechanism, the 'immune system', depends on a constant source of antigens. ${ }^{4}$ It recognises their arrival in the tissues and creates antibodies to eliminate them. In addition, the leucocytes, which are tailored to eliminate undesirable organisms, provide a more direct action, devouring them in situ. Clearly this system functions best when supplied with constant small quantities of antigens and probably the safest sources of these are inter-personal airborne organisms and normal skin contact.

There is increasing evidence that children brought up in 'sterile' homes have reduced resistance to invasive organisms, while those brought up in the country, especially on farms, develop better immunity with less asthma and fewer allergies. ${ }^{5}$ It goes further than that because, as most clinicians are aware, the human body is constantly developing cancer cells which are routinely removed by the immune system. Recent research in Cambridge strongly suggests that if the immune system is not well challenged with antigens in childhood (preferably before five) there is a reduced resistance to all antigens, including cancer cells, when older. ${ }^{6}$ While it is no part of a dentist's duty to encourage the introduction of antigens it does place the risk of clinical cross-infection within a wider scenario.

\section{SUMMARY}

The overall evidence suggests that regular small doses of a wide range of pathogens are good for healthy adults and especially good for children. This type of dose would likely be passed on by human skin contact and interpersonal inhalation. It is possible that within a relatively short time, medical opinion will recommend the greater exposure of young children to minor cross infection and not inconceivable that in normal clinical situations, excepting isolation units and surgical procedures, hand washing and skin contact will be preferred to barrier nursing with gloves.

It is very difficult for those in authority to balance the many conflicting priorities in this field. It is also probable that the public perception that 'bacteria are dangerous' will persist for some years but it is the responsibility of the wider medical fraternity to look ahead on the basis of science and logic rather than emotion.

1. National Clinical Guideline Centre (UK). NICE Clinical Guidelines, No. 139. London: NICE, 2012

2. Ryan M A, Christian R S, Wohlrabe J. Handwashing and respiratory illness among young adults in military training. Am J Prev Med 2001; 21: 79-83.

3. Forbes-Haley C E, Bahal P, King P A. Grip in wet environments. Br Dent J 2014; 216: 655

4. Rook G A W. Inflammation and chronic inflammatory disorders: Darwinian medicine and the 'hygiene' or 'old friends' hypothesis. Clin Exp Immunol 2010; 160: 70-79.

5. Von Mutius E, Vercelli D. Farm living: effects on childhood asthma and allergy. Nat Rev Immunol 2010; 10: 861-868.

6. Fox M, Knapp L A, Andrews P W, Fincher C L. Hygiene and the world distribution of Alzheimer's disease. Evol Med Public Health. 2013; 173-186. 